\title{
DAS ATRIBUIÇÕES ADMINISTRATIVAS NA GESTÃO E SUPERVISÃO DO PATRIMÔNIO GENÉTICO BRASILEIRO
}

\author{
ADMINISTRATIVE RESPONSIBILITIES IN THE MANAGEMENT AND \\ SUPERVISION OF THE BRAZILIAN GENETIC HERITAGE
}

\begin{abstract}
MAGNO FEDERICI GOMES
Pós-doutor em Direito Público e Educação pela Universidade Nova de Lisboa-Portugal. Pós-doutor em Direito Civil e Processual Civil, Doutor em Direito e Mestre em Direito Processual, pela Universidad de Deusto-Espanha. Mestre em

Educação pela PUC Minas. Professor do Mestrado Acadêmico em Direito Ambiental e Sustentabilidade na Escola Superior Dom Helder Câmara. Professor Adjunto da PUC Minas e Professor Titular da Faculdade de Direito Arnaldo Janssen. Advogado Sócio do Escritório Raffaele \& Federici Advocacia Associada.

federici@pucminas.br

CARLos Frederico Saraiva de VAsconcelos

Mestrando em Direito Ambiental e Desenvolvimento Sustentável pela Escola Superior Dom Helder Câmara. Professor de Direito Administrativo, Teoria Geral da Interpretação jurídica, Direito do Consumidor e Direito Ambiental pela Universidade Salgado de Oliveira - Universo. Especialista em Direito e Economia da Empresa pela Fundação Getúlio Vargas. Especialista em Contratos com Ênfase em Negócios pela Universidade Gama Filho. Advogado militante.
\end{abstract}

frederico@vsaadvocacia.com.br

\section{RESUMO}

O presente estudo objetivou demonstrar a violação constitucional constante na recente Lei $n^{\circ}$ $13.123 / 2015$, que dita sobre o acesso ao patrimônio genético, sobre a proteção e o acesso ao conhecimento tradicional associado e sobre a repartição de benefícios para conservação e uso sustentável da biodiversidade, que revogou a Medida Provisória $n^{\circ}$ 2.186-16/2001. A recente Lei tomou uma posição centralizadora quanto ao controle e exploração do patrimônio genético existente no País, quando disciplinou que são de competência da União a gestão, o controle e a fiscalização das atividades descritas no ato normativo, desrespeitando o art. 23 (incisos III, VI e VIII) da Constituição da República de 1988 (CF/1988). Para tal compreensão foi feito um estudo da Lei Complementar $n^{\circ}$ 140/2011 em comparação com a legislação em debate, apontando os aspectos geradores do desrespeito à norma constitucional paradigma. Para esta investigação foi utilizado o método hipotético-indutivo, com pesquisa explicativa qualitativa, utilizando-se o levantamento bibliográfico.

Palavras-chave: Competência comum; Federalismo; Lei $n^{\circ} 13.123 / 2015$; Patrimônio genético.

\begin{abstract}
This study plained to demonstrate the constant constitutional violation in recent Law $n^{\circ} 13.123 / 2015$, which said about access to genetic resources, the protection and access to associated traditional knowledge and the sharing of benefits for conservation and sustainable use of biodiversity, and overturned the Provisional Measure $n^{\circ}$ 2.186-16/2001. The recent Law took a centering position on the control and exploitation of the genetic heritage in the country, when disciplined that the Union have competence management, control and supervision of the activities described in the law, disregarding the art. 23 (sections III, VI and VIII) of the Constitution of 1988 (CF/1988). For such an understanding was made a study of Complementary Law $n^{\circ} 140 / 2011$ compared with the legislation in debate, pointing generators aspects of disrespect to constitutional rule paradigm. For this study we used the hypothetical-inductive method, with explanatory qualitative research, using the literature.
\end{abstract}

Keywords: Shared competence; Federalism; Law $\mathrm{n}^{\circ}$ 13.123/2015; Genetic heritage. 

DO PATRIMÔNIO GENÉTICO BRASILEIRO

magno Federici Gomes, Carlos Frederico Saraiva de Vasconcelos

\section{SUMÁRIO}

INTRODUÇÃO. 1 DA MEDIDA PROVISÓRIA N 2186-16/2001 À LEI Nº 13.123/2015 - DAS ATRIBUIÇÕES E COMPETÊNCIAS CRIADAS PARA A PROTEÇÃO DO PATRIMÔNIO GENÉTICO NACIONAL. 2 DO FEDERALISMO E DA COMPETÊNCIA ADMINISTRATIVA DO ART. 23 DA CONSTITUIÇÃO E A SUA VISÃO EM FACE DO INCISO XXIII DO CAPUT DO ART. $7^{\circ}$ DA LEI COMPLEMENTAR N ${ }^{\circ} 140$ DE 8 DE DEZEMBRO DE 2011. 3 DA FORMA CENTRALIZADA DE CONTROLE GESTÃO E FISCALIZAÇÃO QUE DESRESPEITA A COMPETÊNCIA COMUM DA UNIÃO, ESTADOS E MUNICÍPIOS PARA EXERCEREM POLÍTICAS PÚBLICAS AMBIENTAIS E SUAS ATRIBUIÇÕES ADMINISTRATIVAS PARA PROTEGER O MEIO AMBIENTE - ART. 23 (INCISOS III, VI E VIII) DA CF/1988. CONCLUSÃO. REFERÊNCIAS.

\section{INTRODUÇÃO}

A Constituição da República de 1988 (CF/1988), quando trata da proteção ambiental em seu art. 225, não faz distinção entre o ente privado e os públicos, quando se refere à compulsoriedade de sua defesa e preservação, sendo comum a obrigatoriedade da União, Estados, Municípios e Distrito Federal no cuidado com o uso dos bens ambientais, para garantir a sua sadia e sustentável utilização.

Percebe-se que, historicamente, os recursos genéticos e os conhecimentos tradicionais associados têm sido utilizados de forma equivocada e predatória, beneficiando economicamente a poucos, em detrimento da penúria dos seus verdadeiros detentores, promovendo-se uma verdadeira usurpação do patrimônio genético nacional em prol da mais valia financeira. 0 desenvolvimento dos mais diversos produtos das indústrias atuantes no ramo de cosmética, farmacêutica, química entre outras, passa pelo estudo e exploração desse patrimônio genético, que é peculiar de cada País, mas principalmente no Brasil, que dada a sua dimensão continental e a sua enorme biodiversidade e bens naturais ainda desconhecidos, torna o território em um verdadeiro laboratório a céu aberto, jogado a toda sorte de atitudes pouco idôneas de grandes conglomerados financeiros que, muitas vezes, não se importam com a propriedade intelectual desse patrimônio genético, visando apenas a sua exploração com retorno financeiro'.

Para se evitar tais atitudes, foi criada a Convenção sobre Diversidade Biológica (CDB), que representou um importante avanço no âmbito das negociações internacionais, especialmente para os Países em desenvolvimento e com uma megadiversidade como o Brasil.

\footnotetext{
${ }^{1}$ Para aprofundamentos, ver: ARAÚJO, S. M. V. G. de. Origem e principais elementos da legislação de proteção à biodiversidade no Brasil. In: GANEM, R. S. (Org.). Conservação da biodiversidade: legislação e políticas públicas. Brasília: Câmara dos Deputados, 2011. Cap. 10, p. 177-222.
} 

DO PATRIMÔNIO GENÉTICO BRASILEIRO

magno Federici Gomes, Carlos Frederico Saraiva de Vasconcelos

A CDB reconheceu a soberania nacional sobre a biodiversidade, estabelecendo as regras para exploração e repartição de benefícios, decorrente do uso dos recursos genéticos, trazendo para as comunidades tradicionais e indígenas um alento para se evitar a constante investida na busca desses recursos.

Ao estabelecer que cada Estado signatário deveria regular o acesso e a repartição de benefícios, coube ao Brasil efetuar tal função, sendo que para o tema foi editada a Medida Provisória (MP) $n^{\circ}$ 2.186-16/2001, que instituiu regras para o acesso, a remessa e a repartição de benefícios do patrimônio genético, e criou o Conselho de Gestão do Patrimônio Genético (CGPG), como a autoridade nacional, com função normativa e deliberativa sobre as autorizações de tal bem tutelado.

A referida MP foi alvo de duras críticas porque em diversos pontos contradizia a CDB e apresentava inúmeras violações de normas e princípios constitucionais, sendo reeditada ano após ano sem nenhuma alteração, trazendo um enorme prejuízo ao patrimônio genético nacional.

Atento a tal dilema o legislador pátrio tentou retificar tais inconvenientes, editando a Lei no 13.123/2015, mas, de forma imprecisa, ainda manteve em seu texto incorreções técnicas que levam a conflitar com preceitos constitucionais já arraigados, principalmente no que concerne à repartição da competência material na questão de proteção ao meio ambiente cultural e ao patrimônio genético.

0 presente estudo pretende discutir essas incorreções técnicas presentes na Lei $n^{\circ}$ 13.123/2015, especialmente no parágrafo único do seu art. $3^{\circ}$, que vem a ferir estatuído no art. 23 da CF/1988, lançando um comparativo com a Lei Complementar (LC) n 140/2011.

Por fim, pretende-se então lançar uma justificativa da temática proposta, demonstrando que a centralização observada vai contra o federalismo constitucional proposto, e, por sua vez, milita na contramão do sentido preservacionista do art. 225 da CF/1988, que prevê a atuação compulsória do Estado brasileiro, em todas as suas esferas, na defesa e preservação do patrimônio genético para a presente e futuras gerações.

Utiliza-se como método o hipotético-indutivo e a técnica de pesquisa explicativa qualitativa.

Verificar-se-á a seguir as disposições postadas tanto pela MP $\mathrm{n}^{\circ}$ 2.186-16/2001 quanto pela Lei $n^{\circ} 13.123 / 2015$, no que concerne às competências criadas para a proteção do patrimônio genético nacional. 

DO PATRIMÔNIO GENÉTICO BRASILEIRO

MAgno Federici Gomes, Carlos Frederico SARAiva de VAsconcelos

\section{DA MEDIDA PROVISÓRIA No 2186-16/2001 À LEI N 13.123/2015 - DAS ATRIBUIÇÕES E COMPETÊNCIAS CRIADAS PARA A PROTEÇÃO DO PATRIMÔNIO GENÉTICO NACIONAL}

A CDB, quando da sua criação em 1992, teve o intuito garantir a soberania de cada País sobre o seu patrimônio genético, identificando conhecimento tradicional como elemento essencial nas estratégias para a conservação da biodiversidade.

O Brasil como signatário de tal convenção, necessitava de criar um regramento nacional que viesse a corroborar todo o seu texto, regulando o acesso ao patrimônio genético e criando regras para sua proteção e exploração.

Com o intuito de cumprir tal ordenamento, o Governo entendeu que a melhor opção para o Brasil era declarar o Patrimônio Genético como bem da União, pois somente com esse tratamento poderia ter o efetivo controle sobre o acesso aos recursos do patrimônio genético e sobre a repartição dos benefícios oriundos de sua utilização.

Assim foi editada a MP $n^{\circ} 2.052 / 2000$, logo substituída pela MP $n^{\circ} 2.186-16 / 2001$, que foi alvo de inúmeras críticas, principalmente no que concerne à sua constitucionalidade.

Dentre os inúmeros equívocos perpetrados pela MP $n^{\circ} 2186-16 / 2001$, pode-se citar o seu art. $2^{\circ}$, que condicionou a exploração do patrimônio genético existente no País à autorização ou permissão da União, sem se importar com os aspectos do patrimônio genético estar localizado em terras de propriedades particulares ou dos Estados-Membros e Municípios da Federação.

Ficou evidente a forma centralizadora de controle, que escapou à guarida da competência legislativa concorrente dos Estados-Membros para dispor sobre os interesses regionais marcada no art. 24 da CF/1988, pois de acordo com o texto da MP, o Estado-Membro não seria sequer consultado sobre a exploração do patrimônio genético inserido em seu território.

Outro equívoco da MP $\mathrm{n}^{\circ} 2186-16 / 2001$ estava inserido nos seus arts. $6^{\circ}$ e 10 , quando tratou da proteção da qualidade ambiental e da criação do Conselho de Gestão do Patrimônio Genético (CGEN), órgão criado no âmbito do Ministério do Meio Ambiente, de caráter deliberativo e normativo, o qual era composto apenas por representantes de órgãos e de entidades da Administração Pública Federal que detinha competência sobre as diversas ações como coordenar a implementação de políticas para a gestão do patrimônio genético entre outros assuntos. 

DO PATRIMÔNIO GENÉTICO BRASILEIRO

Magno Federici Gomes, Carlos Frederico Saraiva de Vasconcelos

Tal dispositivo conflitava diretamente com o princípio da obrigatoriedade da intervenção estatal, prevista no art. 225, caput, da CF/1988, que impõe ao Poder Público como um todo, e não apenas à União, o dever de defender e preservar o meio ambiente, não podendo apenas um órgão específico cuidar das ações concernentes à tutela e exploração do patrimônio genético nacional.

Por força do art. 10 da MP n 2186-16/2001 concentraram-se nas mãos da União todos os poderes de autorização, fiscalização e controle das atividades de acesso à biodiversidade.

Com relação ainda à criação do CGEN, evidenciou-se que a sua composição seria, exclusivamente, de representantes da Administração Pública Federal, contrariando, novamente comando constitucional, como o insculpido no art. 23 (incisos III, VI e VIII) da CF/1988, que estabelece a competência comum da União, Estados e Municípios para exercerem políticas públicas ambientais e suas atribuições administrativas para proteger o meio ambiente.

Não obstante a intenção do Governo em se adequar aos ditames da CDB, não poderia ser olvidado o disposto no art. 225, caput, da CF/1988, que infere não somente ao ente público Federal o dever defender e preservar o meio ambiente, mas também traz esta compulsoriedade aos outros entes da Federação e à coletividade.

Desta forma, a exclusão da composição do CGEN da sociedade civil e de comunidades tradicionais, principais interessadas na tutela de seus conhecimentos tradicionais, desprezou o princípio da participação popular, deixando uma enorme lacuna de representatividade em seu texto.

Por fim, há de se comentar que nos ditames art. 17 da MP $n^{\circ} 2186-16 / 2001$, o CGEN dispensou do consentimento dos detentores do conhecimento tradicional associado para sua utilização nos casos de relevante interesse público.

Tal assentamento invade o direito das comunidades tradicionais sobre 0 seu conhecimento, as suas técnicas, uma vez que o conceito de relevante interesse público está recheado de subjetividade, podendo o órgão utilizar dessa prerrogativa para explorar o conhecimento tradicional associado dos povos tradicionais sem o seu devido consentimento, prévio e informado.

Urgia então uma dramática reformulação na legislação vigente, uma vez que os atores da proteção legal estavam visivelmente prejudicados, ficando o patrimônio genético relegado à benevolência das ações dos seus exploradores, pois poderiam angariar vantagens por ações inescrupulosas dos membros compositores do conselho, posto que não contaria com um voto 

DO PATRIMÔNIO GENÉTICO BRASILEIRO

magno Federici Gomes, Carlos Frederico Saraiva de Vasconcelos

contra da sociedade civil ou das comunidades tradicionais, verdadeiras interessadas na tutela de seu patrimônio.

Após longa discussão no congresso, com negociações intermináveis e posicionamentos contra e a favor, em 20 de maio de 2015 foi editada a Lei $n^{\circ} 13.123 / 2015$ que procurou em grande parte sanar os equívocos anteriores, mas que, infelizmente, manteve ainda um deslize quanto à concentração de poder nas mãos da União, para gestão, controle e fiscalização das atividades referenciadas, apesar da menção ao disposto no inciso XXIII do caput do art. $7^{\circ}$ da LC $n^{\circ}$ 140/2011, que dita que são ações administrativas da União gerir o patrimônio genético e o acesso ao conhecimento tradicional associado, respeitadas as atribuições setoriais, o que será discutido em outro tópico.

Uma das principais inovações da Lei $n^{0} 13.123 / 2015$ foi sanar o terrível engano da composição do CGEN, que era realizada no âmbito do Ministério do Meio Ambiente e a sua composição era feita apenas por membros do Governo, subtraindo a participação da sociedade civil e das comunidades tradicionais, que atuavam apenas como convidados, o que feria de morte o caput do art. 225 da CF/1988, além do princípio da participação popular.

Nos ditames da nova lei a composição do CGEN será formada por representação de órgãos e entidades da Administração Pública Federal com participação máxima de 60\% (sessenta por cento) e a representação da sociedade civil em no mínimo 40\% (quarenta por cento) dos membros, assegurada a paridade entre setor empresarial, setor acadêmico e populações indígenas, comunidades tradicionais e agricultores tradicionais.

Apesar da exclusão no texto das comunidades quilombolas, deve-se entender ser o rol meramente exemplificativo, não gerando prejuízo de representação de tal setor.

Não obstante as inovações trazidas, urge o seu estudo e apreciação por toda sociedade, para que o bem maior que é o patrimônio genético seja totalmente protegido e gerido de forma eficiente e sustentável.

Surge portanto a necessidade de se discutir acerca do federalismo e da competência administrativa ditada pelo art. 23 da CF/1988, confrontando-o com o ditado pela Lei Complementar $n^{\circ} 140 / 2011$. 

CONSTITUIÇÃO E A SUA VISÃO EM FACE DO INCISO XXIII DO CAPUT DO ART $7^{\circ}$ DA LEI COMPLEMENTAR N 140 DE 8 DE DEZEMBRO DE 2011

O legislador constituinte, ao abrir o Capítulo II do Título III da CF/1988, trouxe elencada as formas de a União gerir as suas atividades, citando também os seus bens, além de diferenciar a competência legislativa privativa e concorrente do ente federal, assim como determinar a sua competência material para proteção ao meio ambiente e do patrimônio cultural, incluído aí o conhecimento tradicional associado.

A gestão do meio ambiente, bem de tamanha preciosidade, dentro de uma extensa área territorial como a do Brasil, deveria contar com uma descentralização federal, necessária para o aumento da eficiência normativa.

Tal ponderação é pacífica na doutrina brasileira, sendo elucidada por Farias quando dita que "historicamente, apurou-se que, em todas as comunidades politicamente organizadas, há descentralização do poder e que este é o modo e o conteúdo da distribuição do poder central que irão definir a forma de Estado"2.

É evidente que o Federalismo é a forma mais harmônica para descentralização política e administrativa, desde que não se choque com as competências hauridas tanto da divisão vertical como horizontal do poder.

Sobre tal tema assim ensina Baracho Júnior:

O papel do governo central e das coletividades-membro de uma federação é configurado em grande medida pela repartição de competências inscrita nas constituições federais.

[...] A constituição brasileira promulgada em 1988 possui ainda reflexos da veia centralizadora das constituições anteriores, apesar de não ser comparada, neste particular, às constituições d 1937 e 1967. Ela define exaustivamente as competências legislativas privativas da União (art. 22) conferindo aos Estados Federados as competências que não the sejam vedadas pela própria constituição (art. 25, § $1^{\circ}$ ). Há competências administrativas comuns (art. 23) e legislativas concorrentes (art. 24), além das competências privativas e concorrentes atribuídas aos Municípios ${ }^{3}$.

${ }^{2}$ FARIAS, P. J. L. Competência federativa e proteção ambiental. Porto Alegre: Sergio Antônio Fabris, 1999, p. 111.

3 BARACHO JÚNIOR, J. A. de O. Proteção do meio ambiente na Constituição da República. Belo Horizonte: Fórum, 2008, p. 129. 

DO PATRIMÔNIO GENÉTICO BRASILEIRO

Apesar da necessidade, o sistema constitucional brasileiro, talvez ainda contaminado pela centralização praticada nas constituições passadas, ainda não conseguiu um eficaz federalismo, remanescendo ainda uma timidez do legislador quando trata das competências legislativas repartidas entres os três entes, como Baracho Júnior:

O caráter centralizador a que me refiro pode ser constatado a partir da análise das matérias constantes dos artigos. 22 e 24 . Os dois dispositivos são quase exaustivos. Não há tema jurídico que esteja fora dos traçados nestes dois artigos, o que esvazia por completo a competência residual dos Estados, prevista no $\S 1^{\circ}$ do art. 25.

[...] O sistema de repartição de competências adotado no Brasil, como observado, utilizou-se de técnica complexa, segundo a qual são definidas competências privativas, competências concorrentes, competências comuns, competências residuais ou remanescentes e competências supletivas ${ }^{4}$.

Importante ressaltar que ao fazer referência à matéria ambiental, principalmente com relação ao manejo e proteção do patrimônio genético, a competência material é comum, elencada no art. 23 da CF/1988, apontando para um federalismo cooperativista.

Sob uma visão maior da defesa e preservação do meio ambiente, Mukai assim disciplina:

Verifica-se que, com a competência comum prevista no art. 23 da CF, desejou o constituinte que fosse ele instrumental de ordem constitucional destinado a dar efetividade ao federalismo cooperativo posto que o Parágrafo único do art. 23reza que 'lei complementar fixará normas para a cooperação entre União e Estados, o Distrito Federal e os Municípios, tendo em vista o equilíbrio do desenvolvimento e do bem-estar em âmbito nacional'.

Pode-se aqui também verificar que foi intenção do constituinte dispor atribuições de ordem administrativa, pois não se utilizou da expressão legislativa ${ }^{5}$.

Uma ressalva é feita pelo mesmo autor que entende que ao ente federado não é dado o poder de ação indistinto e individual dessa competência, não cabendo uma ação sancionatória sem precedentes no que concerne à ameaça ao meio ambiente, devendo ser relevada a competência territorial para legislar sobre o assunto para exercer tal ação ${ }^{6}$.

Assentado o entendimento do uso eficiente do Federalismo, como forma democrática de descentralização do poder, e consequente proteção ambiental, torna-se necessário centralizar

\footnotetext{
${ }^{4}$ BARACHO JÚNIOR, J. A. de O. Proteção do meio ambiente na Constituição da República. Belo Horizonte: Fórum, 2008, p. 133.

${ }^{5}$ MUKAI, T. Direito urbano-ambiental brasileiro. 2. ed. São Paulo: Dialética, 2002, p. 21.

${ }^{6}$ Conforme MUKAI, T. Direito urbano-ambiental brasileiro. 2. ed. São Paulo: Dialética, 2002, p. 21-22. 
DAS ATRIBUIÇÕES ADMINISTRATIVAS NA GESTÃO E SUPERVISÃO DO PATRIMÔNIO GENÉTICO BRASILEIRO

MAgno Federici Gomes, Carlos Frederico Saraiva de VAsconcelos

os esforços para demonstrar a necessidade de conjugar a legislação pátria com a competência material para o uso eficiente dos recursos ambientais, principalmente nas áreas pertencentes a particulares e a outros entes da Federação, sendo que a tendência centralizadora do legislador constituinte deve ser afastada para efetiva ação do Federalismo.

Rammê assim discorre sobre o tema:

O modelo de repartição de competências (legislativas e administrativas) adotado no Brasil teve, pois, inspiração no sistema germânico: no âmbito legislativo, salvo as matérias em que é estabelecida a competência privativa da união, uma boa parte das matérias fica a cargo da União para elaboração de normas gerais, enquanto aos estados federados e aos municípios brasileiros - estes últimos com espaço de atuação mais restrito - cabe a suplementação; no âmbito administrativo são previstas, sem prejuízo às matérias restritas à competência geral da União, competências comuns entre todos os entes da federação, implicando um verdadeiro federalismo cooperativo de execução ${ }^{7}$.

Dessa forma verifica-se que, mesmo dentro de um federalismo cooperativo, a garantia de um mínimo existencial socioambiental só se efetiva com o uso de todas as possibilidades intervencionistas do Poder Público, em todas as suas esferas, posto que as ações materiais devem ser as mais amplas possíveis para que se possa garantir de forma eficaz um meio ambiente sadio e ecologicamente equilibrado.

Machado pondera:

A competência 'comum' estabelece uma comunhão na gestão das matérias apresentadas no art. 23. A Constituição não quer que o meio ambiente seja administrado de forma separada pela União, Estados, Distrito Federal e Municípios. É razoável entender-se que, na competência comum, os entes Federados devem agir conjuntamente.

[...]

0 art. 23 não exclui qualquer ente federativo do exercício da competência. A 'competência comum' é aglutinadora e inclusiva, somando os intervenientes e não diminuindo ou tornando privativa a participação. A competência comum do art. 23 é a de 'zelar pela guarda da Constituição, das leis e das instituições democráticas' ${ }^{8}$.

Com o advento da LC $n^{\circ}$ 140/2011, as ações administrativas decorrentes do exercício da competência comum em matéria ambiental foram ali privilegiadas, uma vez que constou em seu

7 RAMMÊ, R. S. Federalismo Ambiental Cooperativo e mínimo existencial socioambiental: a multidimensionalidade do bem-estar como fio condutor. Veredas do Direito, Belo Horizonte, v. 10, $\mathrm{n}^{\circ} 20$, p. 145-161, jul./dez. 2013, p. 154.

${ }^{8}$ MACHADO, P. A. L. Direito ambiental brasileiro. 23. ed., São Paulo: Malheiros, 2015, p. 179-180. 
DAS ATRIBUIÇÕES ADMINISTRATIVAS NA GESTÃO E SUPERVISÃO DO PATRIMÔNIO GENÉTICO BRASILEIRO

magno Federici Gomes, Carlos Frederico Saraiva de Vasconcelos

texto a ideia da regulamentação infraconstitucional da cooperação entre a União, os Estados, o Distrito Federal e os Municípios em matéria ambiental.

0 texto normativo foi claro quando ponderou que: “art. $7^{\circ}$. São ações administrativas da União: [...] XXIII - gerir o patrimônio genético e o acesso ao conhecimento tradicional associado, respeitadas as atribuições setoriais"'. Com isso, "o federalismo cooperativo (de execução) brasileiro tutela a garantia de um mínimo existencial sócio-ambiental"10 para que a garantia plena da tutela do meio ambiente, no presente caso, do patrimônio genético, seja alcançada.

Machado ainda pondera que a CF/1988 menciona cada atribuição administrativa de cada ente, sendo que, quando ali não está determinado, segue-se a partilha proposta na LC $n^{\circ}$ 140/2011. O acesso ao conhecimento tradicional e gestão do patrimônio genético fica ao encargo da União, respeitadas as atribuições setoriais. A CF/1988 concedeu ao Poder Público a incumbência de fiscalizar as entidades dedicadas à pesquisa e manipulação de material genético, não podendo ficar tal conceito restrito à União, alijando os Estados e os Municípios ${ }^{11}$.

Apesar de Machado ${ }^{12}$ encarar que a expressão "respeitadas as atribuições setoriais", indica que não houve a centralização, no texto da Lei $n^{\circ} 13.123 / 2015$ não se pode sentir esta tendência, ficando claro que caberá à União a gestão, o controle e a fiscalização das atividades descritas no caput do art. $3^{\circ}$ e residualmente seria respeitado o disposto no inciso XXIII do caput do art. $7^{\circ}$ da LC $n^{\circ}$ 140/2011 como forma de exceção. A citada norma dispõe:

Art. $3^{\circ} \mathrm{O}$ acesso ao patrimônio genético existente no País ou ao conhecimento tradicional associado para fins de pesquisa ou desenvolvimento tecnológico e a exploração econômica de produto acabado ou material reprodutivo oriundo desse acesso somente serão realizados mediante cadastro, autorização ou notificação, e serão submetidos a fiscalização, restrições e repartição de benefícios nos termos e nas condições estabelecidos nesta Lei e no seu regulamento.

Parágrafo único. São de competência da União a gestão, o controle e a fiscalização das atividades descritas no caput, nos termos do disposto no inciso XXIII do caput do art. $7^{\circ}$ da Lei Complementar $n^{\circ} 140$, de 8 de dezembro de $2011^{13}$.

\footnotetext{
${ }^{9}$ BRASIL, 2011, art. $7^{\circ}$, inciso XXIII.

10 RAMMÊ, R. S. Federalismo Ambiental Cooperativo e mínimo existencial socioambiental: a multidimensionalidade do bem-estar como fio condutor. Veredas do Direito, Belo Horizonte, v. 10, $n^{\circ} 20$, p. 145-161, jul./dez. 2013, p. 155.

${ }_{11}$ Nesse sentido, MACHADO, P. A. L. Direito ambiental brasileiro. 23. ed., São Paulo: Malheiros, 2015, p. 181.

${ }^{12}$ Conforme MACHADO, P. A. L. Direito ambiental brasileiro. 23. ed., São Paulo: Malheiros, 2015, p. 181.

${ }^{13}$ BRASIL, 2015, art. $3^{\circ}$.
} 

DO PATRIMÔNIO GENÉTICO BRASILEIRO

Magno Federici Gomes, Carlos Frederico Saraiva de Vasconcelos

Se assim não o fosse, o legislador, a reboque do art. 23 da CF/1988, disciplinaria claramente que a competência em gestão ao patrimônio genético seria comum.

Apesar da LC $n^{\circ}$ 140/2011 trazer avanços no exercício da competência executiva em matéria ambiental, com relação à gestão do patrimônio genético deveria o legislador tomar uma atitude menos centralizadora, ampliando efetivamente a cooperação federativa material.

Urge a necessidade de estudo sobre o controle de gestão e fiscalização centralizados e a sua referência com a competência comum dos entes federados em matéria de exercício de políticas públicas e suas atribuições administrativas, como maneira de proteção ao meio ambiente.

\section{DA FORMA CENTRALIZADA DE CONTROLE GESTÃO E FISCALIZAÇÃO QUE DESRESPEITA A COMPETÊNCIA COMUM DA UNIÃO, ESTADOS E MUNICÍPIOS PARA EXERCEREM POLÍTICAS PÚBLICAS AMBIENTAIS E SUAS ATRIBUIÇÕES ADMINISTRATIVAS PARA PROTEGER O MEIO AMBIENTE - ART. 23 (INCISOS III, VI E VIII) DA CF/1988}

Foi discorrido no tópico anterior sobre a competência comum material ditada pelo art. 23 da CF/1988 e os avanços trazidos pela LC $n^{\circ}$ 140/2011, mas entende-se que na análise conjunta do art. 225 da CF/1988, ainda assim, o texto do parágrafo único do art. $3^{\circ}$ da Lei $n^{\circ}$ $13.123 / 2015$ é centralizador.

Isso porque, em matéria ambiental, a participação do Poder Público é compulsória para a defesa e preservação do meio ambiente para a presente e futura geração, sem distinção entre os seus entes e as suas esferas administrativas.

Não houve pelo legislador constituinte uma diferenciação entre os entes que compõem o Poder Público, sendo eles de forma comum obrigados, tanto na esfera da União, dos Estados Membros e dos Municípios, assim como da Administração direta e indireta.

Não houve também uma ordem de preferência para tutela e proteção do meio ambiente, sendo comum a todos os entes públicos, independentemente da importância ou relevância do ente, pois o que se visa é o trato com o bem maior que é o meio ambiente. 

DO PATRIMÔNIO GENÉTICO BRASILEIRO

Magno Federici Gomes, Carlos Frederico Saraiva de Vasconcelos

0 patrimônio genético como item que compõe a classificação do meio ambiente, podendo pertencer ao meio ambiente natural ou cultural é o bem maior a ser protegido, independentemente da gestão do patrimônio genético estar reservada à União.

Segundo Machado:

A Lei complementar 140/2011 impôs uma ressalva na competência dos Estados, visando à observância da competência mais ampla da União. A ressalva ou a limitação imposta tem a função de alertar as ações estaduais, para que respeitem as ações já tomadas pela União. Aí, como em outras matérias reitero meu entendimento que 0 acolhimento da ressalva depende de um posicionamento autoablativo dos Estados, pois eles são detentores da competência 'comum' constitucional ${ }^{14}$.

Todas as parcelas da sociedade, assim como todos os membros da Federação devem estar envolvidos na vigilância do uso adequado do patrimônio genético, não cabendo uma centralização em um órgão atrelado ao Ministério do Meio Ambiente com a função de coordenar a elaboração e a implementação de políticas para a gestão do acesso ao patrimônio genético e ao conhecimento tradicional associado e da repartição de benefícios.

O órgão em questão é o CGEN, que traz na sua composição, como já foi explanado anteriormente, representantes de órgãos e entidades da Administração Pública Federal e da sociedade civil, sem que ali seja encontrada a participação dos outros órgãos e entes da federação, que, na efetividade, sentem muito mais os efeitos dos atos contra o patrimônio genético, do que a União, que está tão distante quanto a solução destes problemas.

Então é nítida a centralização da competência na União, apesar do texto normativo tentar dizer o contrário e utilizar como ressalva o inciso XXIII do art. $7^{\circ}$ da LC $n^{\circ} 140 / 2011$, onde devem ser respeitadas as atribuições setoriais.

Quais atribuições são estas? Quais setores são estes? Qual o campo de incidência e a amplitude dessas atribuições?

Todas essas respostas serão encontradas somente na análise do caso concreto e na confecção e consolidação de uma jurisprudência que, certamente será vacilante no início, face aos conflitos que se apresentarem, até que se pacifique um entendimento próprio.

E nesse meio tempo, quem perde é o meio ambiente, quem perde é a coletividade.

Exemplos muito mais valorosos com relação à distribuição da competência já foram dados em legislações ícones anteriores, como o estatuído pela Lei $n^{\circ}$ 6.938/1981 quando

\footnotetext{
${ }^{14}$ MACHADO, P. A. L. Direito ambiental brasileiro. 23. ed., São Paulo: Malheiros, 2015, p. 182.
} 

DO PATRIMÔNIO GENÉTICO BRASILEIRO

Magno Federici Gomes, Carlos Frederico Saraiva de Vasconcelos

disciplinou sobre o licenciamento ambiental e o seu consequente exercício do poder de polícia, devendo ser copiado ou ao menos absorvido os seus ensinamentos, uma vez que já traz uma prática segura de anos de uso.

Silva em seu magistério ensina:

0 art. 23 da Constituição dispõe sobre a competência material comum da União, dos estados, do Distrito Federal e dos Municípios. Essa competência diz respeito à prestação de serviços referentes àquelas matérias, à tomada de providências para sua realização.

Alguns incisos do artigo referem-se à proteção do meio ambiente natural e cultural, assim, é que se atribui àquelas entidades, cumulativamente, a competência para proteger obras e outros bens de valor histórico, artístico e cultural, os monumentos, as paisagens naturais notáveis e os sítios arqueológicos (inciso III), bem como a competência para impedir a distribuição e a descaracterização de obras de arte e de outros bens de valor histórico, artístico ou cultural (inciso IV). Já no tocante ao meio ambiente natural encontramos a competência comum para protegê-lo e para combater a poluição em florestas, a fauna e a flora (inciso VII). Essa é uma competência mais voltada para a execução das diretrizes, políticas e preceitos relativos à proteção ambiental ${ }^{15}$.

Não se admite hoje em dia, com a consolidação dos institutos democráticos e a descentralização cooperativa, o legislador assumir uma postura centralizadora velada, para ter o domínio nas ações sobre o patrimônio genético, relegando a um segundo plano a real preocupação com o meio ambiente, a gestão do bem de interesse comum e os interesses das comunidades tradicionais.

Freitas assim ponderou sobre a matéria em:

No inciso III o constituinte deu particular destaque à proteção do patrimônio histórico, artístico e cultural, inclusive paisagens naturais notáveis e sítios arqueológicos. Não foi gratuita a outorga de competência comum, mas fruto do conhecido descaso da população brasileira por suas riquezas, principalmente pelas relacionadas com o aspecto cultural. Cultiva-se, ainda, a ideia do sacrifício de bens históricos ou de paisagens belas em troca do progresso material a qualquer custo, As nossas cidades históricas permaneceram intocadas e hoje constituem rico acervo patrimonial histórico e arquitetônico, mais pelo abandono econômico a que se viram relegadas do que pela ação das autoridades administrativas. Só a elevação da educação e cultura do povo brasileiro fará com que se altere o comportamento de desprezo às nossas poucas lembranças da vida nos séculos passados ${ }^{16}$.

\footnotetext{
${ }^{15}$ SILVA, J. A. da. Direito ambiental constitucional. 4. ed. São Paulo: Malheiros, 2002, p. 77.

${ }^{16}$ FREITAS, V. P. de. A Constituição Federal e a efetividade das normas ambientais. 3. ed. São Paulo: Revista dos Tribunais, 2005, p. 75.
} 
Importante ressaltar que, em face da competência comum, não há de se importar com quem seja o detentor do bem ou o ente que legislou a respeito, qualquer ente da Federação pode atuar conjunta ou separadamente na tutela e proteção ao meio ambiente, não cabendo exceção ao Federalismo cooperativo.

Bates citado por Freitas, quando da discussão sobre a resolução de controvérsias encontradas no exercício da competência entre os entes federados na Austrália, assim sugere:

[...] No caso de um conflito de posições entre as várias autoridades governamentais, deve haver algum mecanismo para determinar a prioridade entre elas. Se não chegarem a um acordo, a legislação sob a qual os poderes são garantidos deve ser voltada para determinar se foi intenção do Parlamento favorecer a determinação de uma autoridade sobre a outra. Às vezes a legislação é bem explícita de que haverá prioridade; mais frequentemente não é ${ }^{17}$.

Este é o caso da legislação brasileira, onde claramente tomou-se um posicionamento centralizador, apesar de aceitar a exceção de a competência ser cumprida por um outro ente da Federação, mas, efetivamente, exclui essa possibilidade, posto que na composição do CGEN, determinou-se a sua composição apenas de representante da União, negando a participação igualitária do Poder Público como um todo na defesa e preservação do patrimônio genético nacional, como foi a intenção do art. 225 da CF/1988.

Assim, como forma de se garantir os direitos de quarta dimensão, que é o direito à democracia, o direito à informação e o direito ao pluralismo, para uma sociedade aberta para o futuro, em sua dimensão de máxima universalidade, deve-se sempre enaltecer o seu expoente maior que é o direito a vida, a partir da abordagem genética e suas atuais decorrências, devendo a atividade estatal se desenvolver em atenção aos parâmetros delineados pelo ordenamento jurídico, e dessa forma, deve respeitar os direitos fundamentais das pessoas assegurados no texto constitucional.

Não se discute se a União teria mais ou menos competência, no sentido de habilidade, eficiência para gerir e coordenar o uso do patrimônio genético nacional, o que se discute aqui é a necessidade de se abrir a todos os entes da Federação a participação comum em sua gestão, como previu o art. 23 da CF/1988.

Assim, como forma de se garantir os direitos de quarta dimensão, que é o direito à democracia, o direito à informação e o direito ao pluralismo, para uma sociedade aberta para o

${ }^{17}$ BATES apud FREITAS, V. P. de. A Constituição Federal e a efetividade das normas ambientais. 3. ed. São Paulo: Revista dos Tribunais, 2005, p. 79. 

DO PATRIMÔNIO GENÉTICO BRASILEIRO

Magno Federici Gomes, Carlos Frederico Saraiva de Vasconcelos

futuro, em sua dimensão de máxima universalidade, deve-se sempre enaltecer o seu expoente maior que é o direito a vida, a partir da abordagem genética e suas atuais decorrências, devendo a atividade estatal se desenvolver em atenção aos parâmetros delineados pelo ordenamento jurídico e, desse modo, deve respeitar os direitos fundamentais das pessoas assegurados no texto constitucional.

\section{CONCLUSÃO}

A CDB, firmada em 1992, assegura aos Países detentores de recursos genéticos soberania sobre o seu patrimônio, e identifica o conhecimento tradicional como elemento essencial nas estratégias para a conservação da biodiversidade.

De maneira geral, verificou-se que o legislador constituinte, apesar da ideia da implantação de um Federalismo descentralizador, ainda deixou obscura a matéria referente às competências ambientais.

Quando se trata de competência material, somente em 2011, com a edição da LC $n^{\circ}$ 140/2011, é que se possibilitou modernizar tal entendimento e trazer para efetividade o verdadeiro exercício da competência comum sem a limitação das matérias e área de atuação de cada ente, bem como as exceções a elas atinentes.

A MP $n^{\circ}$ 2186-16/2001 foi criada para suprir a lacuna deixada pela falta de legislação que viesse a atender os desígnios de regulamentação e convalidação nacional da $C D B$, sendo reeditada ano após ano, sem se importar com as suas ilegalidades e suas inconstitucionalidades.

A Lei $n^{\circ} 13.123 / 2015$ foi criada para revogar o texto da MP $n^{\circ} 2186-16 / 2001$ e adequar as suas incongruências, mas permaneceu com algumas inconsistências como o desprezo ao comando constitucional do art. 23 (incisos III, VI e VIII), que estabelece a competência comum da União, Estados e Municípios para exercerem políticas públicas ambientais e suas atribuições.

Ficaram, então, concentrados na União todos os poderes de autorização, fiscalização e controle das atividades de acesso à biodiversidade, sem se importar com o estabelecido no art. $23 \mathrm{da} C \mathrm{CF} / 1988$.

O controle firmado se justifica, mais especificamente, pela composição do CGEN, pois esse conselho é composto apenas de representantes de entidades governamentais federais, 
DAS ATRIBUIÇÕES ADMINISTRATIVAS NA GESTÃO E SUPERVISÃO DO PATRIMÔNIO GENÉTICO BRASILEIRO

magno Federici Gomes, Carlos Frederico Saraiva de Vasconcelos

excluindo-se assim a presença de entes dos Estados-membros e Municípios, apesar de ter evoluído e incluído membros da sociedade civil como setores empresarial, acadêmico, populações indígenas, comunidades tradicionais e agricultores tradicionais.

A ação governamental na manutenção do equilíbrio ecológico, considerando o meio ambiente como um patrimônio público a ser protegido, deve ser feita sem exceção por todos os seus entes federados, como assegura o art. 225 da CF/1988.

Deve-se respeitar, acima de tudo, os direitos fundamentais das pessoas assegurados no texto constitucional e previstos dentro do rol de direitos de quarta dimensão.

É, portanto, temerária a posição do legislador ao conferir, de forma velada, somente à União a gestão, o controle e a fiscalização das atividades descritas no caput do art. $3^{\circ}$ da Lei $n^{\circ}$ 13.123/2015, admitindo, apenas como exceção, nos termos do disposto no inciso XXIII do caput do art. $7^{\circ}$ da LC n 140/2011, o uso da competência material comum.

\section{REFERÊNCIAS}

ARAÚJO, Suely Mara Vaz Guimarães de. Origem e principais elementos da legislação de proteção à biodiversidade no Brasil. In: GANEM, Roseli Senna (Org.). Conservação da biodiversidade: legislação e políticas públicas. Brasília: Câmara dos Deputados, 2011. Cap. 10, p. 177-222. Disponível em

<http://www.researchgate.net/profile/Suely_Araujo/publication/259292671_Origens_e_Princip ais_Elementos_da_Legislao_de_Proteo_Biodiversidade_no_Brasil/links/Odeec52acc79af1e15000 000.pdf>. Acesso em: 04 jul. 2015.

BARACHO JÚNIOR, José Alfredo de Oliveira. Proteção do meio ambiente na Constituição da República. Belo Horizonte: Fórum, 2008.

BRASIL. Constituição (1988). Constituição da República Federativa do Brasil. Diário Oficial da União, Brasília, 05 out. 1988. Disponível em:

<http://www.planalto.gov.br/ccivil_03/Constituicao/Constituicao.htm>. Acesso em: 02 jun. 2015.

BRASIL. Lei $n^{\circ} 13.123$, de 20 mai. 2015. Regulamenta o inciso II do $\S 1^{\circ}$ e o $\S 4^{\circ}$ do art. 225 da Constituição Federal, o Artigo 1, a alínea j do Artigo 8, a alínea c do Artigo 10, o Artigo 15 e os $\S \S 3^{\circ}$ e $4^{\circ}$ do Artigo 16 da Convenção sobre Diversidade Biológica, promulgada pelo Decreto $n^{\circ}$ 2.519, de 16 de março de 1998; dispõe sobre o acesso ao patrimônio genético, sobre a proteção e o acesso ao conhecimento tradicional associado e sobre a repartição de benefícios para conservação e uso sustentável da biodiversidade; revoga a Medida Provisória ${ }^{\circ}$ 2.186-16, de 23 de agosto de 2001; e dá outras providências. Diário Oficial da União, Brasília, 14 maio 2015. 
Disponível em: <http://www.planalto.gov.br/ccivil_03/_Ato2015-2018/2015/Lei/L13123.htm>. Acesso em: 30 jun. 2015.

BRASIL. Medida Provisória $n^{\circ} 2.186-16$, de 23 ago. 2001. Regulamenta o inciso II do $\S 10$ e o $\S 40$ do art. 225 da Constituição, os arts. 10, 8o, alínea "j", 10, alínea "c", 15 e 16, alíneas 3 e 4 da Convenção sobre Diversidade Biológica, dispõe sobre o acesso ao patrimônio genético, a proteção e o acesso ao conhecimento tradicional associado, a repartição de benefícios e o acesso à tecnologia e transferência de tecnologia para sua conservação e utilização, e dá outras providências. Diário Oficial da União, Brasília, 24 ago. 2001. Disponível em:

<http://www.planalto.gov.br/ccivil_03/mpv/2186-16.htm>. Acesso em: 30 jun. 2015.

FARIAS, Paulo José Leite. Competência federativa e proteção ambiental. Porto Alegre: Sergio Antônio Fabris, 1999.

FREITAS, Vladimir Passos de. A Constituição Federal e a efetividade das normas ambientais. 3. ed. São Paulo: Revista dos Tribunais, 2005.

MACHADO, Paulo Affonso Leme. Direito ambiental brasileiro. 23. ed., São Paulo: Malheiros, 2015.

MUKAI, Toshio. Direito urbano-ambiental brasileiro. 2. ed. São Paulo: Dialética, 2002.

RAMMÊ, Rogério Santos. Federalismo Ambiental Cooperativo e mínimo existencial socioambiental: a multidimensionalidade do bem-estar como fio condutor. Veredas do Direito, Belo Horizonte, v. 10, $n^{\circ} 20$, p. 145-161, jul./dez. 2013. Disponível em:

<http://www.domhelder.edu.br/revista/index.php/veredas/article/view/380/369>. Acesso em: 30 jun. 2015.

SILVA, José Afonso da. Direito ambiental constitucional. 4. ed. São Paulo: Malheiros, 2002.

Recebido em: 18.03.2016 / Revisões requeridas em: 28.04.2016 / Aprovado em: 06.05.2016 